\title{
PENGARUH RETURN ON INVESTMENT OF HUMAN CAPITAL (ROIHC), EFEKTIFITAS TERHADAP KINERJA ORGANISASI STUDI KASUS PADA PT TGU TIRTATAMA JAKARTA
}

\author{
BASUKI RANTO*
}

Abstract: The purpose of research is to determine the effect of Return On Investment of Human Capital (ROIHC), Effectifity with Performance Organization. A survey was conducted at the PT TGU Tirtatama once of entreprises who distibution activity. The research concludes that there are as follow: (1) there is direct effect of the ROIHC on performance organization, (2) there is direct effect of the effectivity on performance organization, (3) Moreover there is direct effect between the ROI of human capital, effectivity perception with the performance organization. Therefore, the performance organization can be improved by enhancing through the ROI of human capital and effectivity.

Keywords: Return on Investment of Human Capital, Capability, Effectivity and Performance.

\section{PENDAHULUAN}

PT TGU Tirtatama sebagai sebuah perusahaan swasta dalam melaksanakan kegiatan usaha berorientasi pada peroleh laba yang maksimal dari sumberdaya dan sumber dana yang dimiliki untuk sepenuhnya mendapatkan hasil yang diharapkan. Sebagai perusahaan yang didirikan 21 tahun yang lalu, bergerak dibidang perdagangan dan distribusi minuman dengan posisi sebagai Agen penjualan (Sales Outlet) yaitu posisi distribusi yang langsung berada dibawah distributor, sehingga memiliki omzet yang ditarget dan daerah tertentu yang perlu dijangkau untuk dilayani. Dengan perjalanan perusahaan yang berangkat dari perusahaan kecil yang kemudian terus bergerak maju dengan perkembangan yang dimulai dengan armada mobil distribusi dua buah yang diperoleh dari leasing kemudian terus meningkat sampai jumlah 20 buah dengan memanfaatkan tenaga kerja dari 7 orang kemudian menjadi 187 orang menunjukkan bahwa perusahaan semakin berkembang,

Dengan misi yang ditetapkan yaitu menjadi perusahaan distribusi yang unggul dan melayani tepat waktu. Untuk mewujudkan Visi tersebut maka ditetapkan missi: melayani dengan hati, menjadikan mitra sejati, membina semangat bersinergi dan memberi bukti bukan janji. Visi dan Missi tersebut ditunjang dengan sebuah motto kerja : jujur, kerja keras, ikhlas dan terus berubah adalah merupakan komitmen dari seluruh lapisan kekuatan mulai dari pelaksana, supervisor, manager sampai dengan Direksi serta stakeholder. Guna mencapai hal tersebut diperlukan kapabilitas dari sumber daya manusia yang dilibatkan dalam proses operasional baik sberkait kepada fungsi administrative maupun teknis. Peran tersebut menjadi kebutuhan substansial dalam rangka memberikan pelayanan yang baik untuk memberikan kepuasan kepada pelanggan.

Kapabilitas dimaksudkan untuk merespon kebutuhan sumber daya yang handal dan profesional dalam rangka tuntutan persaingan bisnis yang kian kompetitif dengan menawarkan keuanggulan yang dimiliki. Melalui kapabilitas dapat meningkatkan kualitas sumber daya manusia yang memiliki kompetensi dan kualifikasi yang baik dan

\footnotetext{
${ }^{*}$ Direktur BUMD DKI Jakarta.
} 
terus menerus ditingkatkan sehingga mampu membentuk Human Capital dalam arti bukan sekedar mampu beraktifitas secara baik tidak sekedar menghasilkan nilai uang (value of money) namun harus lebih kadar kualitasnya dalam menciptakan nilai tambah (value added) yang pada gilirannya mewujudkan penciptaan nilai baru (create value) melalui inovasi yang terus menerus tak berhenti pada suatu titik kepuasan tertentu. Halhal tersebut sesungguhnya yang memaknai Human Capital yang secara organisasi dapat dijadikan handalan dalam memainkan peran dalam persaingan apalagi dalam era globalisasi. Keunggulan harus diciptakan dari berbagai sisi tidak saja keunggulan kompetitif (competitive advantage) tetapi juga keunggulan komparatif (comparative advantage) yang dapat dijadikan senjata pamungkas dalam sebuah persaingan.

Untuk menciptakan keunggulan tersebut diperlukan biaya yang tidak kecil, hal ini menjadi bagian yang harus dipersiapkan dengan baik agar sumber daya yang dimiliki berkemampuan baik dari kemampuan tehnis (technical skill), kemampuan beradabtasi (human skill) maupun kemampuan administratif (administrative skill). Melalui proses pelatihan harus ditingkatkan menjadi pembelajaran, sehingga bukan hanya training centre akan tetapi diperlukan learning centre yang dijadikan sebagai kawah candra dimuka dalam meningkatkan potensi dan kompetensi yang mampu memberikan knowledge kepada semua yang terlibat dalam operasional maupun manajemen. Pengeluaran yang digunakan untuk membangun kapabilitas dan knowledge tentu saja besar dan secara perlakuan akuntansi keuangan tidak bisa dibebankan sebagai biaya pada periode berjalan, sehingga atas biaya learning baik sifatnya formal dan non formal education tersebut dianggap sebagai investasi dan menjadi modal dalam bentuk potensi sumber daya manusia ( Human capital) dalam jangka panjang.

Sebagai sebuah investasi dalam bidang human capital, maka sesungguhnya invesatasi tersebut harus menghasilkan penghasilan dalam bentuk laba bersih (return) dari penciptaan nilai baru sebuah inovasi dan dikaitkan dengan jumlah pendapatan yang akan digunakan untuk mengembalikan investasi. Inilah sesungguhnya hakikat dari konsep Return On Investment of Human Capital ( $R O I-H C$ ) yaitu jumlah investasi yang dikeluarkan untuk membentuk Human Capital dan tingkat pengembalian yang dihasilkan yang diukur dari penciptaan nilai atas knowledge. Melalui ROI-HC diharapkan mampu menghasilkan efektifitas kerja yang tinggi dalam arti percepatan, perputaran, keakuratan, kehandalan, ketepatan, efisiensi serta peningkatan kualitas hasil yang pada gilirannya hal tersebut dapat meningkatkan kinerja organisasi yang dikontribusi oleh individual, kelompok maupun totalitas organisasi dalam bentuk peningkatan kinerja (increasing performance) dan nilai korporasi (corporate value). Hal-hal tersebut yang melatar belakangi dilakukan penelitian untuk mengungkap seberapa pengaruh : Return on Investment of Human Capital, Efektifitas dan Kinerja Organisasi.

Banyak variabel yang mempengaruhi kinerja selain variable tersebut diantaranya : motivasi, lingkungan, budaya, komunikasi, sarana, persepsi, hubungan dan variabel lainnya, namun dalam hal ini hanya dibatasi pada tiga variable yaitu ROIHC, efektifitas dan Kinerja Organisasi.

\section{Kinerja Organisasi.}

Kinerja menurut Ivansevich, Donald dan Gibson (1989 : 2003) mengatakan bahwa kinerja merupakan serangkaian hasil kerja kegiiatan manajemen yang memberikan gambaran sejauh mana hasil yang sudah dicapai dalam melaksanakan tugas dan tanggung jawabnya dalam bentuk akuntabilitas publik baik dalam bentuk keberhasilan maupun kekurangan yang terjadi. Kinerja merupakan Job performance yaitu adanya semangat kerja dimana didalamnya termasuk beberapa nilai keberhasilan baik 
bagi organisasi maupun individu. Kotter dan Haskett (1997 : 2-3) membedakan jenis kinerja yaitu : kinerja ekonomis, menghasilkan etos kerja yang kuat dan berkualitas, sementara disisi lain kinerja yang unggul, yaitu menghasilkan produk unggulan. Disamping iru diperlukan hasil kerja yang mampu diukur dengan tolok ukur yang dispekati. Dari kondisi terebut dapat dikatakan bahwa jenis kinerja dapat diklasifikasikan sebagai kinerja manusia, kinerja mesin dan kinerja organisasi/perusahaan. Hasil kinerja tersebut harus mampu menghasilkan ukuran kinerja melalui efisiensi maupun efektifitas, yang pada gilirannya mampu menghasilkan etos kerja dan kualitas kerja yang unggul.

Dessler (2004 : 2) menyebutkan, dalam rangka menilai kinerja diperlukan langkah-langkah : (1) mendefinisikan pekerjaan; (2) menilai kinerja; (3) memberikan umpan balik dan adanya akuntabilitas yang jelas. Ivancevich (2002 : 149-150) mengatakan bahwa penilaian kerja yang efektif sekaligus memberikan pengaruh dua hal yaitu produktivitas dan kualitas kerja. Dalam menilai kinerja dapat dilakukan dengan beberapa pendekatan baik melalui pendekatan keuangan maupun pendekatan non keuangan yang harus memiliki tolok ukur nilai yang dapat diyakini dan mampu memberikan standart penilaian yang dapat dipertanggungjawabkan, sehingga terdapat perlakuan yang dapat diyakini.

Dari beberapa pendapat tersebut dapat disintesiskan bahwa penilaian kinerja adalah serangkaian hasil kerja dalam melakukan kegiatan usaha baik produktifitas, pengembangan usaha, efisiensi dan efektifitas dengan beberapa indikator : semangat kerja, kualitas kerja, produk unggulan, keberhasilan dan akuntabilitas.

\section{Return On Investment OI of Human Capital (ROIHC)}

Human Capital merupakan elemen yang penting dalam organisasi koroporasi, karena human capital sebagai asset tidak berwujud (intangilble asset) bisa dalam bentuk: hak cipta, hubungan pelanggan, merk dan image perusahaan baik dalam bentuk goodwill maupun reputasi manajemen. Bontis et al (1999) mendefinisikan: "Human capital represents the human factor in the organization; the combined intelligence, skill and expertises that give of organi9zation its distinctive character. The humam elements of the organization are those that are capable of learning, changing, innovating and providing the creative thrust which if properly motivated can ensure the long-term survival of the organization"

Scarborough and Elias (2002) menyatakan :'The concept of human capital is most usefully viewed as a bridging concept - that is, if defines the link between Human relation (HR) practice and business performance if term of asset rather than business processes'. Nilai yang ingin disampaikan dalam difinisi tersebut adalah human capital bukan hanya hal-hal yang sifatnya standar saja akan tetapi berkit kepada dinamika organisasi dan bagian dari unsur manusia yang memiliki kompentensi yang kuat. Intellectual Capital merupakan bagian yang diperlukan dalam Human Capital. Intellectual Capital merupakan kemampuan knowledge yang dimiliki dan termasuk dalam intangible asset. Edvinson and Malone (2007) menyebutkan terdapat tiga elemen dalam intellectual capital yaitu: (1) Human Capital - the knowledge, skills, abilities and capacity to develop and

innovate possessed by pople in organization: (2) Social Capital- structure, networks and procedure dan (3) Organization Capital - the institutionalized possessed by organization that stored in databases, manuals etc. 
Human Capital Return on Investment (HCROI) sebagaimana dimaksud oleh JAC FITS - ENZ (209) menyebutkan : "relationship of human capital investments to profitability can be made visible through a ratio that follows from the formula for human capital value added (HCVA)". Dengan demikian HCROI adalah merupakan hubungan antara investasi HC dengan tingkat pendapatan yang mampu dihasilkan dengan menggunakan formula dari HCVA. Formula untuk menghitung HCVA menurut Stern Stewart (1990) adalah : HEVA = Net Operating profit after tax - cost of capital/Full time equivalent (FTE). Formula tersebut menggambarkan bahwa HCVA adalah merupakan selisih antara laba bersih setelah pajak dengan biaya atas modal dibagi dengan tingkat equvalent waktu penuh yaitu hasil yang diperoleh dari sejumlah pegawai pada waktu tertentu. Sementara cost of capital adalah biaya atas penggunaan modal (pinjaman) yang merupakan bebean tetap yang dinyatakan dalam prosentasi sedangkan EFT adalah merupakan Equivalent Full Time yaitu tingkat nilai yang dihasilkan oleh beberapa personel (team) dalam waktu tertentu.

Untuk menghitung HCROI digunakan formula : Reveneue - (Expenses- Pay and Benefit/Pay and benefit. Lebih lanjut dari formula tersebut dapat dijelaskan bahwa HCROI adalah merupakan selisih antara Pendapatan yang diterima dengan beban biaya dikurangi pembayaran dan manfaat dan dibagi pembayaran dan manfaat. Penerimaan pendapatan adalah merupakan hasil yang diperoleh dari investasi human capital, sedangkan beban adalah pengeluaran yang digunakan untuk investasi HC yang diamortisasi pada setiap periode sebagai beban periode berjalan, sementara pembayaran adalah bentuk absolud yang dikeluarkan kepada employee dan manfaat lain dalam bentuk intangible.

\section{Efektifitas}

Ivancevich dan Matteson (1996:20) mengemukakan bahwa keefektifan organisasi dapat dilihat dari tiga level yakni : individual, kelompok dan organisasi. Hal tersebut berkait dengan tuntutan tanggung jawab yang harus dilakukan terhadap pelaksanaan fungsi yang secara substansi dan essensi juga dibedakan kepada tanggung jawab individu, kelompok dan organisasi. Mullin (2005 : 959) mengemukakan bahwa efektifitas organisasi akan ditentukan oleh efisiensi dan produktifitas organisasi. Efisiensi merupakan suatu kondisi bagaimana dapat melaksanakan dengan benar, memanfaatkan sumberdaya secara minimal dalam menghasilkan produk atau jasa.sedangkan produktifitas adalah kemampuan untuk menghasilkan sesuatu dengan benar dengan memperhatikan ratio antara input dan output yang mampu menghasilkan produk dan jasa yang berkualitas.

Robbins dan Judge ( 2007 : 27 ) mengemukakan bahwa keefektifan diartikan sebagai pencapaian tujuan. Dengan demikian efektifas berkait kepada efisiensi dan produktivitas. Hal tersebut sejalan dengan apa yang dikemukan sebelumnya. Terdapat dua pendekatan efektifitas sebagaimana dikemukakan Ivancevich dan Matteson (2007: 20) yaitu : (a) the goal approach dan (b) the system theory approach. Pendekatan yang pertama diarahkan kepada bagaiamana organisasi mampu secara eksis mencapai tujuan yang telah ditetapkan, sedangkan pendekatan berikutnya diarahkan kepada suatu konsep teori perilaku internal dan ekternal terhadap faktor yang dapat mempengaruhi keberhasilan pencapaian tujuan.

Terdapat lima kategori dalam mencapai effektitas organisasi sebagaimana dikemukakan oleh Gibson (2001:7) yaitu : efisiensi; efektitas; kepuasan karyawan; adaptasi dan kemampuan memperoleh sumber daya. sebkinerja merupakan 
serangkaian kegiatan manajemen yang memberikan gambaran sejauhmana hasil yang sudah dicapai dalam melaksanakan tugas dan tanggung jawabnya dalam bentuk akuntabilitas publik baik berupa keberhasilan maupun kekurangan yang terjadi. Kinerja merupakan job performance, adanya semangat kerja di mana di dalamnya termasuk beberapa nilai keberhasilan baik bagi organisasi maupun individu.

\section{METODE.}

Tujuan operasional dari penelitian ini adalah untuk mengungkapkan hubungan antara : (1) ROIHC dengan kinerja organisasi, (2) Efektifitas organisasi dengan kinerja organisasi, dan (3) ROIHC dan efektifitas secara bersama-sama dengan kinerja organisasi. Penelitian dilakukan di PT TGU Tirtama Jakarta. Penelitian dilakukan mulai awal desember 2009 sampai dengan akhir Februari 2010. Populasi penelitian adalah para pegawai level manajemen madya yaitu manajer dan supervisor dengan jumlah sampel sebanyak 60 orang yang diambil secara acak. Pengumpulan data dengan menggunakan instrumen berupa kuesioner.

\section{HASIL PENELITIAN}

\section{Deskripsi Data}

Penelitian ini mengukur empat variabel kinerja organisasi $(Y)$, $\operatorname{ROIHC}\left(\mathrm{X}_{1}\right)$, dan effetifitas $\left(\mathrm{X}_{2}\right)$, yang dilakukan terhadap 60 responden. Setiap variabel di ukur secara terpisah melalui instrumen penelitian berupa kuesioner. Deskripsi data setiap variabel dirangkum pada tabel 1.

Tabel 1. Deskripsi Data Variabel X \& Y

\begin{tabular}{|l|c|c|c|}
\hline Statistik & $\mathbf{X}_{\mathbf{1}}$ & $\mathbf{X}_{\mathbf{2}}$ & $\mathbf{Y}$ \\
\hline Skor Maks. & 141.00 & 38.00 & 209.00 \\
\hline Skor Min. & 105.00 & 13.00 & 121.00 \\
\hline Mean & 123.33 & 25.22 & 160.57 \\
\hline Median & 126.43 & 25.50 & 159.50 \\
\hline Modus & 122.58 & $20^{\mathrm{a}}$ & $158^{\mathrm{a}}$ \\
\hline Simp. Baku & 10.29 & 5.99 & 13.50 \\
\hline
\end{tabular}

Keterangan

$\mathrm{X}_{1}=$ Variabel ROIHC

$\mathrm{X}_{2}=$ Variabel Efektifitas

$\mathrm{Y}=$ Variabel kinerja organisasi

Pengujian Persyaratan Analisis

Uji Normalitas

Uji normalitas di dalam penelitian ini menggunakan Liliefors test. Rangkuman perhitungan dapat dilihat pada tabel berikut :

Tabel 2. Hasil Normalitas Data Variabel X \& Y 


\begin{tabular}{|c|c|c|c|c|c|}
\hline Galat Taksiran & \multirow{2}{*}{\begin{tabular}{c}
\multirow{2}{*}{ Regresi $Y$ atas } \\
\cline { 4 - 5 }
\end{tabular}} & & \multicolumn{2}{|c|}{ D.Maks } & Keterangan \\
\cline { 4 - 5 } & & & $\alpha=0,05$ & $\alpha=0,01$ & \\
\hline$X_{1}$ & 60 & 0,085 & 0,1144 & 0,1331 & Normal \\
\hline$X_{2}$ & 60 & 0,076 & 0,1144 & 0,1331 & Normal \\
\hline$X_{3}$ & 60 & 0,079 & 0,1144 & 0,1144 & Normal \\
\hline
\end{tabular}

\section{Keterangan :}

$\mathrm{D}_{\text {-maks }}=$ Nilai $\mathrm{D}$ maks berdasarkan perhitungan

$\mathrm{D}_{\text {-tabel }}=$ Nilai $\mathrm{D}$ taraf signifikan $\alpha=0,05 \& \alpha=0,01$

Dapat disimpulkan dari tabel 2. bahwa semua data dalam variabel penelitian ini berasal dari populasi yang berdistribusi normal.

\section{Uji Homogenitas}

Uji Homogenitas varians populasi dilakukan dengan menggunakan uji Bartlett. Rangkuman hasil perhitungan dapat dilihat pada tabel berikut.

Tabel 3. Hasil Uji Homogenitas Varians Populasi

\begin{tabular}{|c|c|c|c|c|c|}
\hline \multirow{2}{*}{ Varians $Y$ atas $X$} & \multirow{2}{*}{$\mathrm{dk}$} & \multirow{2}{*}{$\chi_{\text {hitung }}^{2}$} & \multicolumn{2}{|c|}{$\chi_{\text {tabel }}^{2}$} & \multirow{2}{*}{ Keterangan } \\
\cline { 4 - 6 } & & & $\alpha=0,05$ & $\alpha=0,01$ & \\
\hline$X_{1}$ & 33 & 18,33 & 43,77 & 48,28 & Homogen \\
\hline$X_{2}$ & 20 & 20,09 & 31,410 & 63,69 & Homogen \\
\hline
\end{tabular}

Tabel 3. menunjukkan bahwa keseluruhan harga $\chi_{\text {hitung }}^{2}$ lebih kecil dibanding $\chi_{\text {tabel }}^{2}$. hal ini berarti bahwa varians populasi homogen.

\section{Pengujian Hipotesis}

Pengujian hipotesis bertujuan untuk menguji tiga hipotesis penelitian yaitu :

Terdapat pengaruh positif antara ROIHC dengan kinerja organisasi.

Berdasarkan perhitungan regresi sederhana terhadap data variabel Produktivitas $(Y)$ atas ROIHC $\left(X_{1}\right)$ diperoleh model regresi $\ddot{Y}=78,869+0.662 X_{1}$. Berdasarkan hasil pengujian signifikansi dan linearitas disimpulkan bahwa regresi $\hat{Y}=78,869+0,662 X_{1}$, sangat signifikan dan linear. Regresi ini mengandung arti bahwa apabila Perilaku Kepemimpinan meningkat satu unit, maka Produktivitas cenderung meningkat sebesar 0,662 pada konstanta 78,869.

Model pengaruh antara variabel perilaku kepemimpinan dengan Variabel produktivitas dapat ditampilkan dengan model persamaan $\ddot{Y}=78,869+0,662 X_{1}$, seperti pada grafik 1 . 


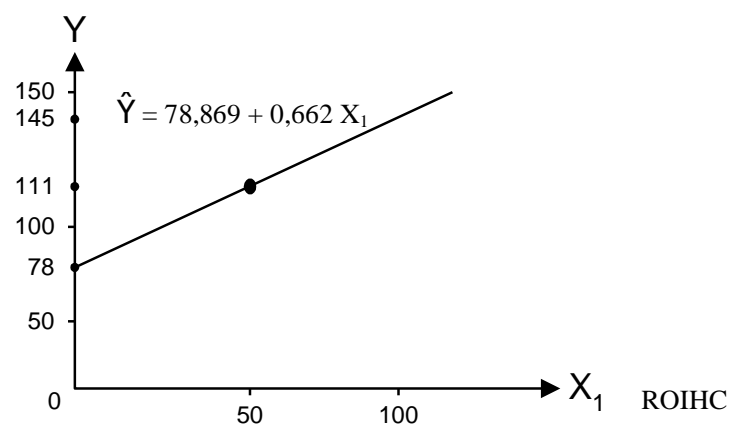

Gambar 1. Grafik Regresi Linear Sederhana Pengaruh antara variabel Perilaku Kepemimpinan dengan variabel produktivitas.

Kekuatan pengaruh antara variabel $\mathrm{X}_{1}$ dengan variabel $\mathrm{Y}$ ditunjukkan oleh koefisien korelasi product moment sebesar $\mathrm{r}_{\mathrm{y} 1}=0,51$. Uji keberartian koefisien korelasi dengan uji $\mathrm{t}$ didapat harga $\mathrm{t}_{\text {hitung }}$ sebesar 4,45, sedangkan pada $\alpha=0,05 \mathrm{dan} \mathrm{dk}=58$ didapat $t_{\text {tabel }}=1,68$. Berdasarkan hasil pengujian signifikansi ternyata bahwa korelasi $X_{1}$ dengan $Y$ sangat signifikan. Dengan demikian Hipotesis penelitian terbukti bahwa terdapat pengaruh positif antara variabel ROIHC dengan Variabel Kinerja Organisasi atau hipotesis penelitian teruji kebenarannya. Dengan kata lain semakin baik ROIHC akan semakin meningkat Kinerja Organisasi.

Koefisien determinasi merupakan kuadrat dari koefisien korelasi antara variabel $X_{1}$ dengan variabel $Y$ yaitu sebesar $\left(r_{y 1}\right)^{2}$ atau $(0,51)^{2}=0,2601$ yang berarti bahwa $26,01 \%$ variasi yang terjadi pada Kinerja organisasi dapat dijelaskan oleh melalui $\ddot{Y}=78,869+$ $0,662 X_{1}$. Apabila dilakukan pengontrolan terhadap variabel Efeektifitas $\left(X_{2}\right)$ didapat koefisien korelasi parsial sebesar $\mathrm{r}_{\mathrm{y} 1.2}=0,438$. Uji signifikan korelasi parsial didapat harga sebesar $t_{\text {hitung }}=7,99$, sedangkan pada $\alpha=0,01$ dengan $\mathrm{dk}=57$ didapat $\mathrm{t}_{\text {tabel }}=2,423$. Karena $t_{\text {hitung }}(7,99)>t_{\text {total }}(2,42)$, maka berarti koefisien korelasi parsial signifikan.

Selanjutnya apabila dilakukan pengontrolan terhadap variabel Efektifitas $\left(\mathrm{X}_{2}\right)$, maka diperoleh koefisien korelasi parsial sebesar $\mathrm{r}_{\mathrm{y} 1.2}=0,4162$. Uji keberartian korelasi parsial dengan uji t didapat harga $t_{\text {hitung }}$ sebesar 7,76. Pada $\alpha=0,01$ diperoleh tabel sebesar 2,423dan pada $\alpha=0,05$ diperoleh $t_{\text {tabel }}$ sebesar $=1,684$. Karena harga $t_{\text {hitung }}(7,76)>t_{\text {tabel }}(2,423)$, dapat disimpulkan bahwa koefisien korelasi parsial sangat signifikan. Pada $\alpha=0,05$ diperoleh sebesar 1,684. Karena harga $t_{\text {hitung }} 7,76>1,684$ dapat disimpulkan bahwa koefisien korelasi parsial sangat signifikan. Berdasarkan uji keberartian tersebut dapat disimpulkan bahwa terdapat pengaruh yang signifikan antara ROIHC $\left(\mathrm{X}_{1}\right)$ dengan Kinerja Organisasi $(\mathrm{Y})$ baik dikontrol $\mathrm{X}_{2}$ sendiri-sendiri maupun $\mathrm{X}_{2}$ secara bersama-sama.

\section{Pengaruh antara Efisiensi dengan Kinerja Organisasi}

Hipotesis kedua dalam penelitian ini yaitu terdapat pengaruh positif antara $\mathrm{X}_{2}$ dengan $\mathrm{Y}$. Perhitungan analisis regresi sederhana pada data variabel $\mathrm{Y}$ atas $\mathrm{X}_{2}$ menghasilkan arah regresi b sebesar 0,972 dan konstanta a sebesar 136,060. Dengan demikian bentuk hubungan antara kedua variabel tersebut dapat digambarkan oleh 
persamaan regresi $\ddot{Y}=136,060+0,972 X_{2}$. Sebelum digunakan untuk keperluan prediksi, persamaan regresi ini harus memenuhi syarat kelinearan dan keberartian. Berdasarkan hasil pengujian signifikansi dan linearitas disimpulkan bahwa regresi $\ddot{Y}=136,060+0,972 X_{2}$, sangat signifikan dan linear. Regresi ini mengandung arti bahwa apabila Efektifitas dapat ditingkatkan satu unit, maka Kinerja Organisasi cenderung meningkat sebesar 0,972 pada konstanta 136,060.

Model pengaruh antara variabel Efektifitas dengan variabel Kinerja Organisasi dapat ditampilkan dengan model persamaan $\ddot{Y}=136,060+0,972 X_{2}$, seperti pada grafik 2 .

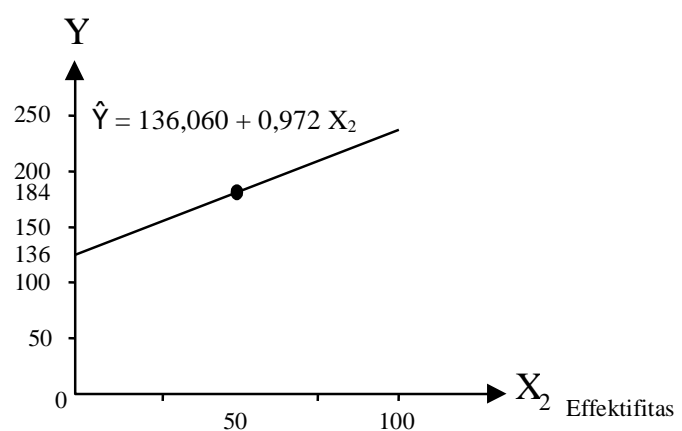

\section{Gambar 2. Grafik Regresi Linear Sederhana Pengaruh Efektifitas} dengan Kinerja Organisasi

Kekuatan hubungan antara variabel Persepsi Kebijakan dengan variabel Produktivitas ditunjukkan oleh koefisien korelasi product moment sebesar $\mathrm{r}_{\mathrm{y} 2}=0,431$. Uji keberartian koefisien korelasi dengan uji $t$ didapat harga $t_{\text {hitung }}$ sebesar 8,42. Koefisien determinasi merupakan kuadrat dari koefisien korelasi antara variabel Efektifitas dengan variabel Kinerja Organisasi yaitu sebesar $\left(\mathrm{r}_{\mathrm{y} 2}\right)^{2}=(0,431)^{2}=0,186$ yang berarti bahwa $18,60 \%$ variasi yang terjadi pada Kinerja Organisasi dapat dijelaskan oleh Kebijaksanaan melalui $\ddot{Y}=136,060+0,972 \mathrm{X}_{2}$.

Apabila dilakukan pengontrolan terhadap variabel ROIHC didapat koefisien korelasi parsial sebesar $r_{\mathrm{y} 2.1}=0,338$. Hasil Uji signifikan didapat $t_{\text {hitung }}=2,85$, sedangkan dari daftar tabel $\mathrm{t}$ pada $\alpha=0,01$ dengan $\mathrm{dk}=58$ didapat harga $\mathrm{t}$ hitung $=$ 2,85 . Karena $t_{\text {hitung }}(2,85)>t_{\text {tabel }}(1,684)$, maka berarti koefisien korelasi parsial sangat signifikan. Selanjutnya apabila dilakukan pengontrolan terhadap variabel ROIHC dan variabel Efektifitas, maka diperoleh koefisien korelasi parsial sebesar $r_{\mathrm{y} 2.13}=$ 0,3150 . Hasil uji signifikan didapat harga $t_{\text {hitung }}=2,49$. Sedangkan dari daftar tabel $t$ pada $\alpha=0,01$ dengan $d k=58$ didapat harga $t_{\text {tabel }}=1,684$. Karena $t_{\text {hitung }}(2,49) t_{\text {tabel }}>$ $(1,684)$, berarti korelasi parsial sangat signifikan.

Harga indeks koefisien korelasi parsial tersebut menunjukkan bahwa apabila dilakukan pengontrolan terhadap variabel bebas lainnya mengakibatkan terjadinya penurunan kadar hubungan dari variabel tanpa pengontrolan, namun tetap dapat memberikan gambaran hubungan positif dan sangat signifikan antara Efektifitas dengan Kinerja Organisasi. 


\section{Pengaruh antara ROIHC dan Efektifitas secara bersama-sama dengan Kinerja Organisasi.}

Perhitungan regresi jamak data variabel Kinerja Organisasi atas ROIHC dan efektifitas menghasilkan arah regresi a sebesar 0,492 untuk variabel ROIHC, a sebesar 0,612 untuk variabel Efektifitas, sedangkan konstanta sebesar 60,869. Dengan demikian bentuk pengaruh antara variabel bebas dengan variabel terikat tersebut dapat digambarkan oleh persamaan regresi $\ddot{Y}=60,869+0,492 X_{1}+0,612 X_{2}$. Sebelum digunakan untuk keperluan prediksi, persamaan regresi ini harus dilakukan uji keberartian regrasi. Berdasarkan hasil pengujian signifikansi dan linearitas dapat disimpulkan bahwa regresi $\hat{Y}=60,869+0,492 X_{1}+0,612 X_{2}$ sangat signifikan. Kekuatan korelasi jamak antara variabel ROIHC dan variabel Efektifitas dengan variabel Kinerja Organisasi menghasilkan koefisien korelasi sebesar $\mathrm{R}=0,634$. Uji keberartian dengan menggunakan uji $\mathrm{F}$ sebesar $\mathrm{F}_{\text {hitung }}=12,572$.

Dari hasil pengujian signifikan dapat disimpulkan bahwa koefisien korelasi jamak yang diperoleh dalam penelitian ini sangat signifikan. Temuan ini membuktikan bahwa terdapat hubungan positif antara ROIHC dan Efektifitas secara bersama dengan Kinerja Organisasi telah teruji kebenarannya. Koefisien determinasi adalah sebear $R^{2}=0,4019$. Ini menunjukkan bahwa 40,19 persen variasi yang terjadi pada variabel Kinerja Organisasi dapat dijelaskan secara bersama-sama oleh ROIHC dan Efektifitas melalui $\ddot{Y}=60,869+0,492 X_{1}+0,612 X_{2}$.

\section{KESIMPULAN DAN SARAN}

Kesimpulan. Kinerja Organisasi dapat ditingkan melalui peningkatan ROIHC yang baik, Efektifitas yang tinggi. Peningkatan knowledge, kompetensi, learning secara terprogram dan terus menerus diperlukan dalam membangun human capital sehingga dapat dijadikan keunggulan, yang pada gilirannya akan meningkatkan hasil yang mampu mengembalikan investasi human capital. Efektifitas merupakan hal yang perlu dilakukan melalui respon yang cepat, operasional yang tepat dan kualitas yang baik.

Saran. Pertama, Untuk membangun keunggulan organisasi hendaknya terus ditingkatkan investasi yang berkait dengan human capital melalui learning centre. Kedua, dengan keunggulan yang dimiliki dari sisi human capital, hendaknya mampu meningkatkan hasil (return) organisasi yang mampu mengembalikan investasi human capital. Ketiga, dalam rangka meningkatkan efektifitas organisasi agar terus ditingkatkan sistem control yang memadai dengan penetapan sistem dan prosedur dan fungsi pengendalian yang berbasis kepada sistem informasi, komunikasi dan tehnologi. Keempat, agar kinerja organisasi memberikan gambaran kinerja yang terkoordinasi, kiranya dapat diterapkan sistem penilaian kerja melalui Balance Scorecard. 


\section{DAFTAR RUJUKAN}

Adam, Everett E. Jr James C. Hershauer, William A. Ruch; Productivity and Quality Measurement as a Basis for Improvement. USA:Prentice-Hall, 1981

Adam, Everett E. Jr. Ronald J.Ebert, Production and Operations Management, Concepts, Models, and Behavior, Singapore : Prentice-Hall, Simon \& Schuster (Asia) Pte Ltd. 1996.

Baron, Angela \& Armstrong, Michael, HUMAN CAPITAL MANAGEMENT, Achieving added vaue through people, London : Kogan Page, 2007.

Bateman, Thomas S, Scott A. Snell: Management The New Competitive Landscape. New York: McGraw-Hill / Irwing , 2004.

Blake, Randolph, Robert Sekuler; Perception; USA : McGraw - Hill, 2006

Du Brin, Andrew J.; Essentials of Management. USA : Thomson South-Western, 2003.

Enz, Jac Fitz , ROI of Human Capital- measuring the economic value of employee performance: New York : Amacom, 2009.

Gibson, James L, John M. Ivansevich, James H. Donnaly ;Jr., Robert Konopaske; Organazations Behavior, Structure, Process. USA:McGraw-Hill, 2006.

Gordon, Yudith. R; Organizational Behavior, A Diagnostics Approach. USA: McGraw - Hill, 2006.

Hunger, J.David, Thomas L. Wheelen, Strategic Management. USA : Prentice-Hall, 2000.

Newstrom, John W; Organizational Behavior, Human Behavior at Work, USA: Mc.GrawHill, 2007.

Robbin, Stephen P.; David De Cenzo, Fundamentals of Management Focusing on Quality , Competetiveness. New Jersey :Prentice -Hall, 2003.

Russel, Ruberta S and Bernard, Taylor W.; Fundamental of Management Focusing on Quality, Competitiveness, New Jersey : Prentice - Hall, 2008. 